\title{
Isovistas aplicadas à localização de unidades de informação para mobilidade de pedestres
}

\author{
Isoviews applied to location of information units for \\ pedestrian mobility
}

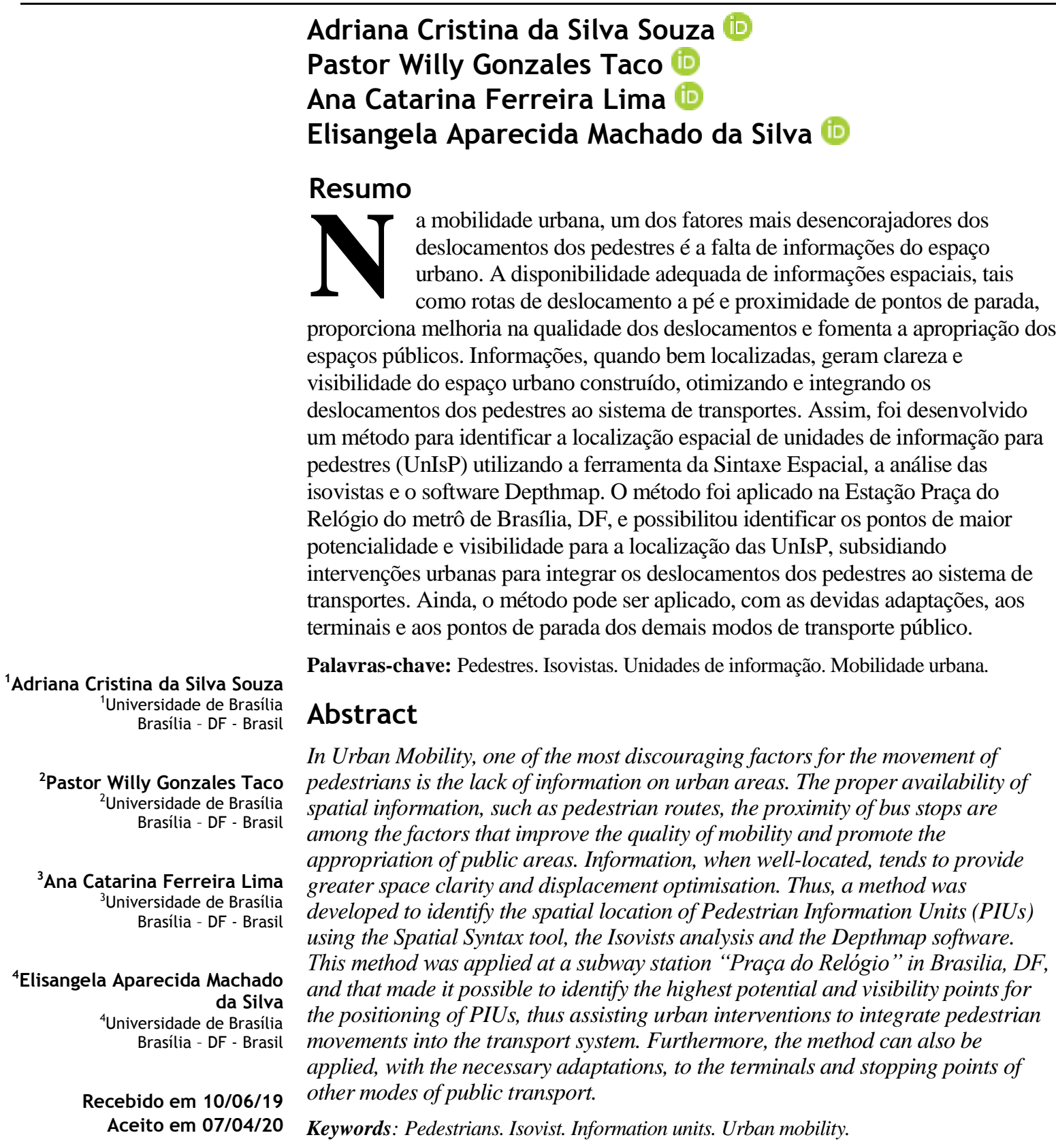

SOUZA, A. C. da S.; TACO, P. W. G.; LIMA, A. C. F. L.; SILVA, E. A M. da. Isovistas aplicadas à localização de unidades de informação para mobilidade de pedestres. Ambiente Construído, Porto Alegre, v. 20, n. 4, p. 407-421, out./dez. 2020. 


\section{Introdução}

Em 2012, o Governo Federal brasileiro publicou a Lei $n^{\circ} 12.587 / 2012$, que instituiu as diretrizes da Política Nacional de Mobilidade Urbana e trouxe em seu art. $6^{\circ}$ a diretriz da prioridade dos modos de transportes não motorizados sobre os motorizados e dos serviços de transporte público coletivo sobre o transporte individual motorizado. Dos modos não motorizados, os deslocamentos a pé ocupam o segundo modo mais utilizado em deslocamentos pelas cidades (CONFEDERAÇÃO..., 2011) e têm sido o modo de transporte que menos recebeu recursos e investimentos nos últimos anos. Além disso, os diversos obstáculos no ambiente urbano para os pedestres, sejam eles com ou sem mobilidade reduzida, têm acarretado limitações distintas, que, quando avaliadas em relação à percepção do espaço e à maneira como se orientam nele, é um dos fatores de maior influência na caminhada (FAYUMI, 2011) e na sua integração ao sistema de transporte público. Como exemplo, é possível citar a falta de calçadas apropriadas, a iluminação precária e a falta de informações do espaço urbano. Pedestres são preteridos em segurança, conforto e informação, enquanto os modos motorizados possuem espaços físicos cada vez maiores e sinalizações mais aprimoradas.

Ainda, dentre os motivos que desestimulam as pessoas a caminharem, está, por exemplo, a falta de infraestrutura contínua e de informações entre a origem e o destino, que aparecem como os fatores mais desencorajadores apontados pelas pessoas na migração ou na integração dos seus deslocamentos diários (FAYUMI, 2011; ECK, 2004). Assim, o fomento ao deslocamento a pé passa pela disponibilização adequada de unidades de informação para pedestres localizadas no espaço construído. As UnIsP sãoelementos físicos, como placas, tótens e mapas de localização, contendo informações sobre a localização do pedestre, as principais rotas, os serviços urbanos oferecidos na proximidade, além do tempo de deslocamento no espaço urbano. Quando disponibilizadas aos pedestres, as UnIsP podem reduzir a incerteza e evitar a ambiguidade na descontinuidade do espaço e favorecer o deslocamento. Também beneficiam e proporcionam melhoria na qualidade da caminhada ao pedestre, aumentando a confiança e a orientabilidade do indivíduo nos deslocamentos, otimizando o tempo de deslocamento, gerando maior apropriação do indivíduo com os espaços públicos e, consequentemente, aumentando as distâncias percorridas e o número de viagens realizadas. Por conseguinte, esse estímulo às viagens pedonais reduz o número de deslocamentos motorizados e contribui para alterar, positivamente, a matriz de mobilidade e a utilização do transporte público.

É de se esperar que nos descolamentos não motorizados, especialmente no deslocamento a pé, o planejamento da cidade deva considerar, primordialmente, a escala humana (GEHL, 2013). Planejar a cidade na escala do pedestre significa produzir espaços que sejam facilmente apreendidos pelas pessoas, o que inclui a produção de informações mais aprimoradas sobre os espaços e os transportes públicos, com detalhes de rotas, pontos de interesse, distâncias e tempo de caminhada (GEHL, 2013), por isso é importante considerar e evidenciar os estudos já citados que considerem a aplicação de tecnologias espaciais em soluções para a mobilidade de pedestres e que promovam a integração desse modo ao sistema de transporte urbano.

É com base nisso que, acredita-se, a disponibilidade de UnIsP tem potencialidade para estimular os deslocamentos a pé. As UnIsP devem conter informações que possibilitem uma leitura contínua do espaço, a indicação de direção e, com isso, a orientação dos pedestres em seus deslocamentos. Nesse sentido, o objetivo do artigo é apresentar os resultados da aplicação do método para localização espacial de UnIsP orientadas ao pedestre em áreas de influência das estações de metrô, no sistema de transporte público de Brasília, no Distrito Federal, fazendo uso da Sintaxe Espacial (isovistas). O método desenvolvido por Souza (2015) foi testado em estudo de caso realizado em 2014/2015, de forma a contribuir para a incorporação do método como ferramenta aplicável ao processo de planejamento de pontos estratégicos para localização de equipamentos de informação aos pedestres (UnIsP).

Inicia-se o artigo por esta apresentação, seguida pela segunda seção com a abordagem teórico-conceitual sobre a Teoria da Sintaxe Espacial (isovistas) e sua relação com a mobilidade urbana. A seguir, na terceira seção é apresentado o método de natureza qualitativa para a determinação da localização das UnIsP. Na quarta seção, por meio de mapas espaciais gerados no software Depthmap,são mostrados os resultados para o estudo de caso e discutidas as contribuições e as limitações deste estudo em relação à literatura existente. E, por fim, na quinta seção são formuladas as conclusões finais. 


\section{Teoria da sintaxe espacial: isovistas aplicadas à mobilidade urbana}

Desenvolvida na década de 1970, na University College London (UCL), a Teoria da Sintaxe Espacial tem por finalidade contribuir para as investigações sobre a forma e a organização do espaço quanto a sua relação e influência nas dinâmicas sociais nas cidades. De acordo com essa teoria, a configuração da malha urbana é considerada um sistema de barreiras e permeabilidades que condicionam o movimento no espaço, contribuindo diretamente para a mobilidade dos pedestres, seja positivamente, por meio de percursos otimizados, seja negativamente, pela sensação labiríntica de determinados espaços urbanos (HILLIER; HANSON, 1984). Medeiros (2013) enfatiza ainda que a Sintaxe Espacial é, em essência, um método de estudo para o espaço urbano, possibilitando que elementos associados à configuração urbana sejam mensurados matematicamente e visualizados graficamente, tornando-se ferramenta com destacada aplicação em pesquisas urbanas com foco nas mobilidades (BARROS, 2006; BARROS et al., 2009; BARROS, 2014; CARMO; RAIA JUNIOR; NOGUEIRA, 2012; NOGUEIRA, 1998; ERA, 2012; FUJITANI; KISHIMOTO, 2012; PEREIRA et al., 2011; RAFORD; RAGLAND, 2003; SOUZA, 2015; VUKAN, 2007).

Compreendem aspectos básicos de representação na Teoria da Sintaxe Espacial o espaço axial, o espaço convexo e a isovista (ELOY, 2011). O espaço axial possibilita a representação do espaço por meio de grafos (axiais ou justificados) nos quais os compartimentos são representados por "nós" e as ligações por "vetores"; essa representação reforça a noção de espaço e do movimento necessário para o percurso, assim como as características de acessibilidade e permeabilidade. O espaço convexo expressa o espaço vazio ou aqueles ocupados representados por formas convexas, convencionalmente feitas de modo a que todos os pontos num polígono sejam visíveis pelos outros pontos do mesmo polígono. A isovista é um polígono de visibilidade que representa o volume de espaço visível de determinado ponto do espaço, ou seja, é uma interação entre a geometria e o movimento, considerando aspectos de percepção e cognição espacial (ELOY, 2011). Portanto, a isovista, denominada nos primeiros estudos de viewshed (AMIDON; ELSNER, 1968; BENEDIKT, 1979; LYNCH, 1976), é utilizada na representação gráfica das feições da terra, da água ou de outros elementos do ambiente visíveis aos olhos humanos; portanto, uma área visível ao observador, tomada como referência em uma localização específica.

Benedikt (1979), por sua vez, o primeiro a aplicar a ferramenta de isovistas na análise de espaços arquitetônicos, apresentando descrições quantitativas sobre o campo de visibilidade, descreve as isovistas como um conjunto de todos os pontos visíveis a partir de determinado ponto escolhido no espaço (observador). Definidas assim, as isovistas permitem analisar as mudanças que ocorrem no campo de visão a partir dos deslocamentos e, desse modo, fornecem uma representação das áreas com maior visibilidade e dos pontos de interesse estratégico.

Franz e Wiener (2005) aplicaram a ferramenta para analisar a influência da morfologia e da configuração espacial no comportamento humano e na experiência de uso do espaço. A partir de experimentos envolvendo descrição dos espaços e navegações em ambientes virtuais, com aplicação de atributos quantitativos simples de isovistas e grafos de visibilidade, o estudo relaciona características qualitativas básicas do espaço, tais como amplitude, permeabilidade, complexidade e ordem. Para os autores, as características visuais e espaciais dos ambientes acabam por servir como ponto de decisão nos deslocamentos.

No estudo de Era (2012), o objetivo não foi testar ou validar a ferramenta, mas compreender fatores da acessibilidade e da qualidade das rotas de deslocamento dos pedestres, a partir de um estudo de caso específico em espaços públicos e rede pedonal da cidade de Granada, na Espanha. Nesse caso, a configuração espacial desempenha um papel crucial na qualidade ambiental da acessibilidade pedestre, determina os fluxos entre diferentes itinerários para chegar aos espaços públicos com suas respectivas condições e características. Uma vez conhecidos o valor de integração dos itinerários e a profundidade do alcance visual, isso permite duas intervenções principais. Primeira, localizar nos espaços públicos equipamentos urbanos em acordo com a tipologia sobre acessibilidade. Segunda, desenhar estratégias de intervenção sobre os espaços públicos em que os itinerários associados apresentam valores de integração significativos. Se esses valores forem aumentados, a atração por espaços públicos também será aumentada.

Em convergência com os estudos supracitados, Barros (2014), ao analisar em que medida a forma urbana (em suas instâncias morfológicas e sintáticas) interfere na mobilidade pedonal no que tange ao estabelecimento de rotas e à interação com o uso do solo e a dinâmica da vida pública, destaca a emergência de estudos sobre o caráter intrínseco do ato de caminhar do ser humano que propicia a interação, o contato entre os indivíduos, os quais expressam a relevância dos elementos do tempo e dos movimentos específicos. 
Como contribuição ao desenvolvimento do método, Souza (2015) utilizou a Sintaxe Espacial (isovista) como ferramenta capaz de propiciar a análise da forma urbana por meio de suas permeabilidades e barreiras, permitindo a identificação de soluções para integrar o pedestre ao sistema de transporte público. A identificação de pontos no espaço urbano para disponibilizar UnIsP (por exemplo, placas, mapas, totens) em pontos estratégicos, articulando o deslocamento de pedestres de um ponto de transferência de transporte ao seu destino final, direciona para rotas/caminhos, constituindo esses como equipamentos urbanos facilitadores da apropriação do espaço pelos indivíduos, o que contribui para o deslocamento contínuo e orientado.

O método apresentado por Souza (2015), aplicado ao estudo de caso do presente artigo e detalhado no próximo tópico, ressalta a relevância dos campos de visão para o posicionamento de unidades de informação, isto é, locais que visualmente são mais fáceis de serem alcançados a partir de determinado espaço na perspectiva do pedestre. A orientabilidade por meio de informações estrategicamente posicionadas modifica culturalmente o significado do espaço e, consequentemente, o espaço em si, transformando-o em lugar, pois simultaneamente são possibilitadas a leitura (ato perceptivo) e a escrita (ato criativo) de um território.

\section{Método para identificação da localização das UnlsP}

O método para identificação da localização das unidades de informação para pedestres (SOUZA, 2015), em sua concepção e aplicabilidade, é fundamentado no referencial teórico descrito anteriormente, enfatizando que as cidades precisam ser planejadas e construídas para pessoas (em escala humana) e que o espaço urbano precisa ser atrativo, convidativo, com elementos de referência que facilitem a orientação e a apropriação do espaço, visando à continuidade, à liberdade e à segurança para se deslocar.

Assim, a concepção do método parte dos seguintes preceitos conceituais:

(a) identificação do ponto de localização espacial de unidade de informação para pedestre: local destinado à instalação do elemento físico (ícones, totens, mapas de sinalização, placas), que traz informações sobre a região ou a área de influência;

(b) definição da área de influência: área virtual estabelecida com raio de $500 \mathrm{~m}$, ponto a partir do qual se encontra o indivíduo em deslocamento a qualquer direção. Assim, consideram-se a mesma distância e tempo de deslocamento a pé em relação aos pontos de interesse (VUKAN, 2007);

(c) divisão da área de influência pelo tempo de percurso: constituída por três áreas, de início, intermediária e final. $\mathrm{Na}$ área de início, identificada com a cor verde (até $5 \mathrm{~min}$ ), o indivíduo possui maior liberdade e facilidade de deslocamento até seu destino final. $\mathrm{Na}$ área intermediária, de cor amarela (maior de 5 min e até $10 \mathrm{~min}$ ), é necessária uma maior atenção para o deslocamento, podendo o pedestre não se lembrar das rotas ou dos percursos mais curtos e simples. A área final, marcada com a cor vermelha (maior de $10 \mathrm{~min}$ ), o pedestre sente a necessidade de encontrar um ponto de referência para orientação até seu destino final;

(d) representação dos caminhos dos pedestres: são geradas as isócronas, definidas como sucessões de linhas que representam a distância em que é possível se deslocar a velocidades constantes, em períodos iguais de tempo (O'SULLIVAN; MORRISON; SHEARER, 2000), ou seja, o caminho que qualquer indivíduo poderá realizar para o seu deslocamento, independentemente da infraestrutura existente (como passeios, calçadas); e

(e) delimitação das áreas de visibilidade: é a área de referência para o pedestre, ou seja, o indivíduo consegue, a partir de um primeiro ponto, enxergar o segundo, gerando um entendimento da continuidade da rota (percurso).

Definidos os preceitos, a aplicação do método ao caso do metrô de Brasília, DF, compreende quatro fases (Figura 1): na primeira fase, todo o sistema metroviário do estudo de caso é caracterizado a partir dos seguintes dados: demanda do sistema com o número de passageiros embarcados e desembarcados por estação no período de um ano, uso do solo nas áreas de influência das estações, sistema viário e rotas dos pedestres nas proximidades das estações. Ainda nesta fase, objetiva-se gerar as informações para serem utilizadas em um sistema de coordenadas geográficas. Na segunda fase, as áreas de influência das estações são caracterizadas com o auxílio do sistema de informações geográficas (SIG), por meio da geração das informações em layers. Para o estudo de caso, o software utilizado foi o Depthmap. É quando as estações mais representativas do sistema são escolhidas tendo como base o fluxo de passageiros e a representatividade dos usos do solo. 
Figura 1 - Esquema de desenvolvimento do método

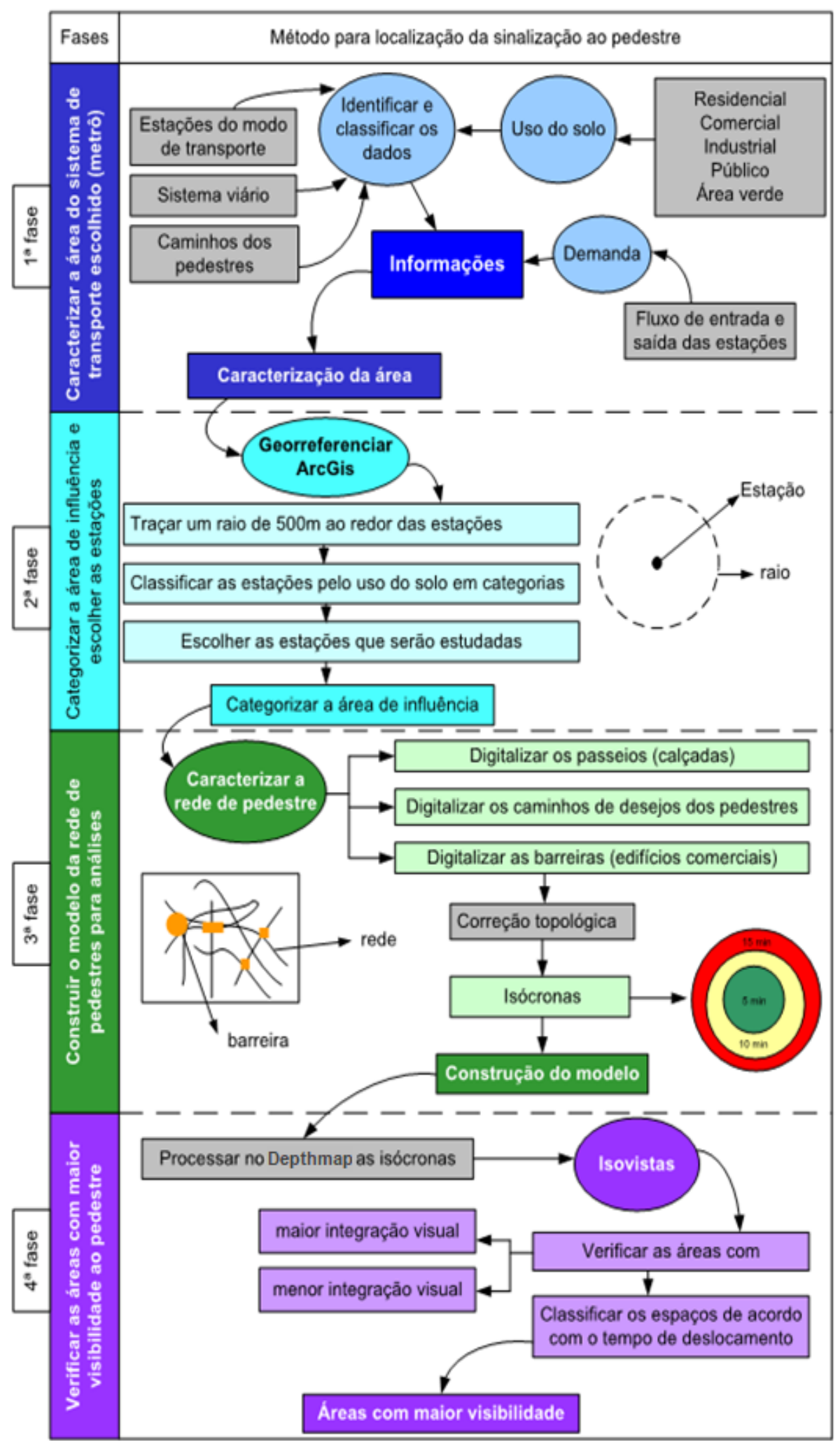

Fonte: Souza (2015).

Na terceira fase, o modelo da rede de rotas de deslocamento do pedestre é construído levando em consideração todas as barreiras e calçadas presentes. Entende-se por barreira nesta pesquisa os elementos do ambiente construído, tais como edifícios, ruas com alta velocidade ou quaisquer obstáculos que dificultem 
ou impossibilitem a travessia por pedestres. Uma vez pronta a rede, é possível utilizar a função network analysis, disponível no software de SIG, para gerar as isócronas. Na geração das isócronas, consideram-se a velocidade, a distância e o tempo de deslocamento dos pedestres na rede. A velocidade dos pedestres adotada neste estudo foi de $4 \mathrm{~km} / \mathrm{h}$, conforme apontado no Manual on Uniform Traffic Control Devices (FEDERAL..., 2009).

Na quarta fase, com o auxílio do programa Depthmap, as isovistas são geradas, sendo possível identificar as áreas com maior ou menor visibilidade. A partir desses dados e do tempo de deslocamento nas áreas de influência das estações, sugere-se a localização de informações espaciais para o deslocamento dos pedestres.

Sendo o Distrito Federal o recorte escolhido para determinar a localização de unidades de informação espacial para o deslocamento de pedestres nas áreas de influência das estações do sistema de transporte metroviário, a caracterização da área de estudo e do estudo de caso será descrita nos tópicos seguintes.

\section{Aplicação do método para identificação das UnlsP numa estação do sistema metroviário de Brasília, DF}

Brasília, capital do Brasil, unidade federativa do Brasil, localizada no Centro-Oeste, possui aproximadamente 2,9 milhões de habitantes (INSTITUTO..., 2015), distribuídos pelo território do Distrito Federal (DF). Inaugurada na década de 1960 para abrigar a estrutura política administrativa do país, possui entre as principais características o traçado urbano modernista, com a valorização do transporte rodoviário, grandes vazios urbanos e a setorização de usos do solo. Além disso, em 1987, o Plano Piloto de Brasília foi declarado Patrimônio Histórico da Humanidade pela Unesco, acarretando algumas limitações urbanísticas ao adensamento, ao gabarito e aos usos na área tombada. Diante dessas características, o planejamento do transporte público se mostra desafiador.

A expansão urbana de Brasília é resultado do fenômeno de migração da população, orquestrado por uma política de ocupação do interior brasileiro, potencializada pelas políticas de descentralização dos meios de produção econômica das capitais do Centro-Sul do país, mais especificamente a partir da década de 1980. Durante o período da construção de Brasília, no início dos anos 1950, deslocaram-se diversos migrantes não só para trabalhar em cargos públicos na capital, mas também para auxiliar e construir a cidade. Em cinco décadas, a população do DF passou de 141.742 mil para 2.977.216 milhões de habitantes (COMPANHIA..., 2016), um aumento de $2.000,45 \%$ da população.

Esse fenômeno tem como consequência a expansão territorial do centro em direção à periferia, marcada por toda sorte de desigualdades socioeconômicas e espaciais: população de baixa renda, serviços de saúde e de transportes precários, falta de vagas em creches e escolas, baixo nível de oportunidades de emprego e renda. A rápida ocupação territorial, abrindo espaço para a criação sucessiva das regiões administrativas (RA), foi estendendo-se além dos limites do DF, alcançando os estados de Goiás e de Minas Gerais. Avançando por sobre áreas de proteção ambiental, essa rápida ocupação ocorreu de forma desordenada e sem os mesmos requisitos técnicos de planejamento que em Brasília.

Há 56 anos da fundação da capital, as RA ainda são dependentes das atividades e das estruturas econômicas de Brasília, com exceção de Taguatinga e Ceilândia, com dinâmicas próprias. Contudo, ainda mantêm dependência do núcleo central do DF no que se refere aos serviços públicos e aos serviços de alta complexidade técnica. Isso forma uma centralidade radial em torno de Brasília, que, além de ser a capital política do país, se torna uma centralidade do DF e da Região Integrada de Desenvolvimento do Distrito Federal e Entorno (Ride).

Consequentemente, observa-se em Brasília a predominância dos espaços não edificados sobre os edificados, gerando uma malha urbana fragmentada e descontínua. Segundo Barros e Medeiros (2013), "Brasília filia-se a um fundamento urbanístico peculiar e resulta de uma concepção global (cidade pensada como um todo), seguindo os preceitos da urbanística moderna desenvolvida na primeira metade do século XX, a partir de uma lógica vinculada à Era da Máquina".

Concebido no bojo desse pensamento urbanístico, o metrô de Brasília (Figura 2), em operação desde 2001, conta com 29 estações distribuídas em 42,3 km de via. Apesar de estar implantado no eixo mais populoso da cidade, composto das RA de Taguatinga, Ceilândia, Samambaia, Guará e Águas Claras, atende 160 mil passageiros por dia (METRÔ, 2019). Apresenta uma frota de 32 trens, que ligam a Rodoviária do Plano Piloto a Ceilândia e Samambaia, passando pelo Eixo Rodoviário Sul e pelas regiões administrativas de Guará, Águas Claras e Taguatinga. O sistema opera de segunda a sexta-feira no

412 Souza, A. C. da S.; Taco, P. W. G.; Lima, A. C. F. L.; Silva, E. A M. da 
horário das $6 \mathrm{~h}$ às $23 \mathrm{~h} 30$, e nos finais de semana das $7 \mathrm{~h}$ às $19 \mathrm{~h}$.

Dentre os principais motivos para o baixo uso do sistema público metroviário, destaca-se a extensa presença de áreas monofuncionais, muitas vezes próximas a vazios urbanos. Considerando também que, das 29 estações ativas do metrô de Brasília, 21 delas (mais de 60\%) estão situadas em área predominantemente residencial, 1 predominantemente comercial, 2 predominantemente de áreas verdes, 2 comercial e residencial e 3 comercial e pública, as estações foram classificadas em cinco categorias, de acordo com o uso de solo em que se localiza a estação, conforme exibe a Figura 3.

Figura 2 - Sistema metroviário de Brasília, DF

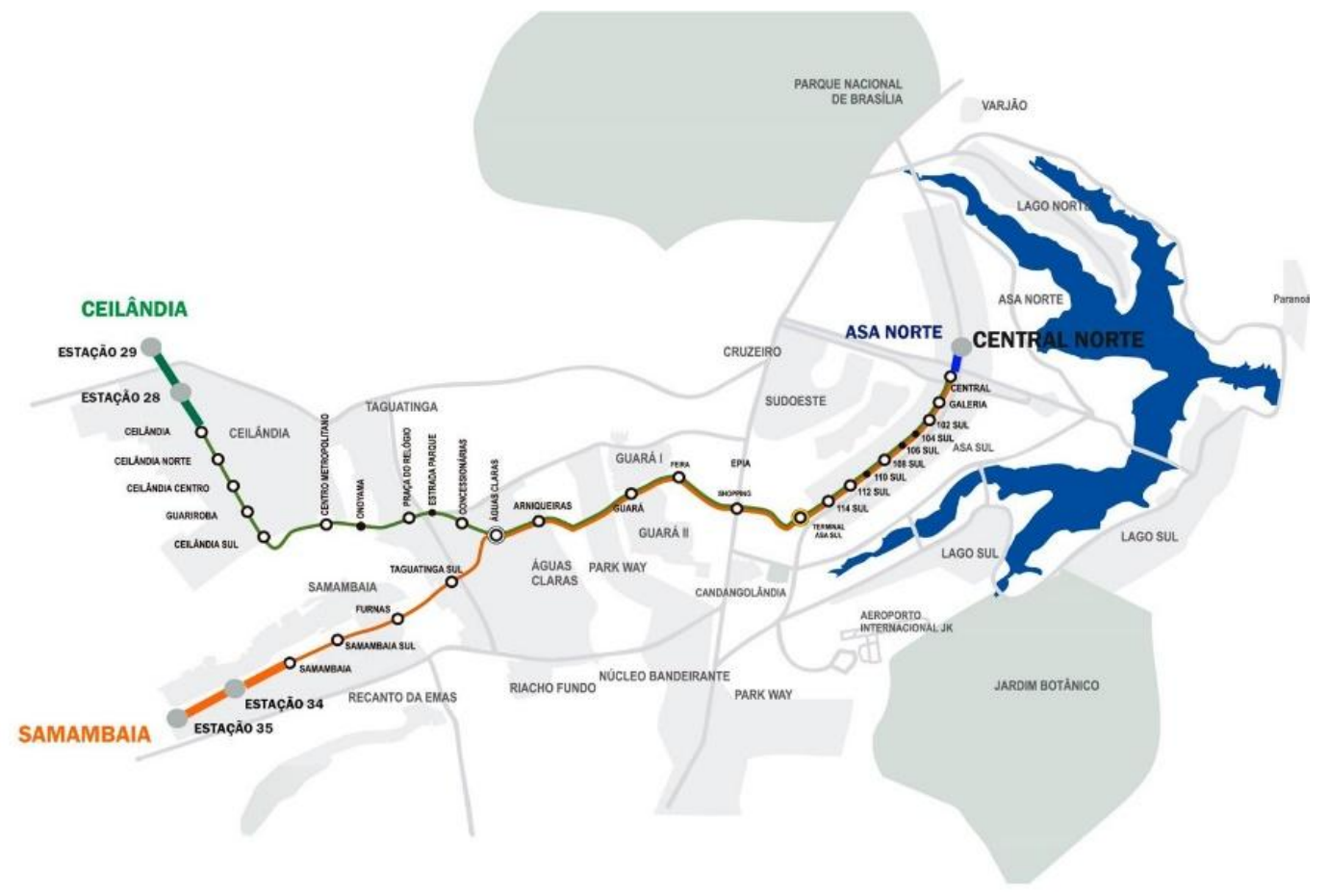

Fonte: Metrô (2019).

Figura 3 - Classificação do uso de solo das estações de metrô



Fonte: Souza (2015). 
No método para localização de sinalização ao pedestre (SOUZA, 2015), as estações metroviárias mais significativas são escolhidas com base em dois aspectos: o uso do solo (o diagnóstico dos diversos tipos de áreas de influência e a rede de pedestres, considerando todo tipo de impedância para o pedestre, ou seja, barreiras que impeçam a livre circulação das pessoas) e o fluxo de entrada e saída de passageiros, conforme mostra a Tabela 1. Além disso, diferentes contextos de estações foram considerados, tanto aqueles com baixo potencial de instalação de UnIsP como aqueles já dotados de pontos estratégicos para essas unidades.

Neste artigo, com a finalidade de testar a aplicabilidade do método, é apresentada a análise de apenas uma entre as cinco estações mais representativas. A estação escolhida é a Estação Praça do Relógio, localizada na RA de Taguatinga, a segunda maior do Distrito Federal, localizada a $17 \mathrm{~km}$ do centro de Brasília. Essa RA é caracterizada por representar o segundo maior polo empregatício do DF e oferecer uma variedade de serviços, gerando contingente significativo de deslocamentos durante todo o dia, principalmente, em horário comercial.

A área de influência da Estação Praça do Relógio é caracterizada pela diversidade de comércio, serviços e habitações multifamiliares. Ali existem escritórios, lojas de departamentos, shopping centers, clínicas e salas comerciais, atraindo um número significativo de usuários do metrô e de moradores próximos, promovendo maior interação/relação com o espaço público.

A Estação Praça do Relógio apresenta uma média de 270 mil passageiros mensais e está localizada em uma região que apresenta usos comerciais de pequeno e médio porte, além de habitações unifamiliares e multifamiliares. Na região existe intenso fluxo durante o horário comercial e o inverso no período noturno. A Figura 4 demonstra os caminhos que os pedestres podem seguir ao sair da estação, nos quais também se encontram indicados alguns tipos de informações aos pedestres.

Seguindo a metodologia apresentada, a partir da construção da rede de pedestres, é possível obter as isócronas da área de influência $(500 \mathrm{~m})$ ao redor da Estação Praça do Relógio. A Figura 5 demonstra o alcance dos deslocamentos a pé durante intervalos predeterminados (5 min, 10 min e $15 \mathrm{~min}$ ).

A caracterização inicial da área em estudo permite identificar os locais potencialmente mais vantajosos para abrigar as UnIsP. Assim, a abordagem parte da configuração da forma urbana para indicar os locais apropriados para equipamentos de informação; não obstante, considera a circulação de pedestres e a disposição do sistema de transportes motorizado, nesse caso as estações de metrô.

\section{Análise dos resultados}

O estudo de caso na Praça do Relógio é de natureza qualitativa, cuja ferramenta de interpretação, a Sintaxe Espacial, requer a decodificação do sistema em barreiras (cheios, que não podem ser vistos e/ou percorridos) e permeabilidades (vazios, que podem ser vistos e/ou percorridos). Nessa etapa, a análise leva em consideração, além das três escalas de aproximação já conhecidas ( 5 min, 10 min e 15 min de caminhada até a estação), três variáveis: área da isovista, raio máximo da isovista e integração visual.

Cabe esclarecer que as modelagens elaboradas a partir da Sintaxe Espacial (isovista) não oferecem como resultado caminhos predefinidos, mas sim manchas ou áreas que apresentam desempenho comum - algumas delas adequadas à localização de UnIsP em razão da abrangência visual ou da proximidade. Entretanto, quando se obtém um conjunto de manchas distribuídas no espaço, é possível traçar uma rede de caminhos interligando-as numa perspectiva de articular as posições hierarquicamente mais vantajosas, estabelecendo um trajeto.

Tabela 1 - Classificação quanto ao uso de solo das áreas de influência das estações

\begin{tabular}{c|c|c}
\hline Estação & Uso do Solo & $\begin{array}{c}\text { Fluxo - Média Mensal } \\
\text { de Passageiros }\end{array}$ \\
\hline Galeria & Comercial e pública & 221.067 \\
Shopping & Predominantemente comercial & 258.352 \\
Guará & Predominantemente residencial & 162.641 \\
Praça do Relógio & Comercial e residencial & $\mathbf{2 7 7 . 1 3 2}$ \\
Furnas & Áreas verdes e residencial & 132.034 \\
\hline
\end{tabular}

Fonte: Souza (2015). 
Figura 4 - Área de influência da Estação Praça do Relógio

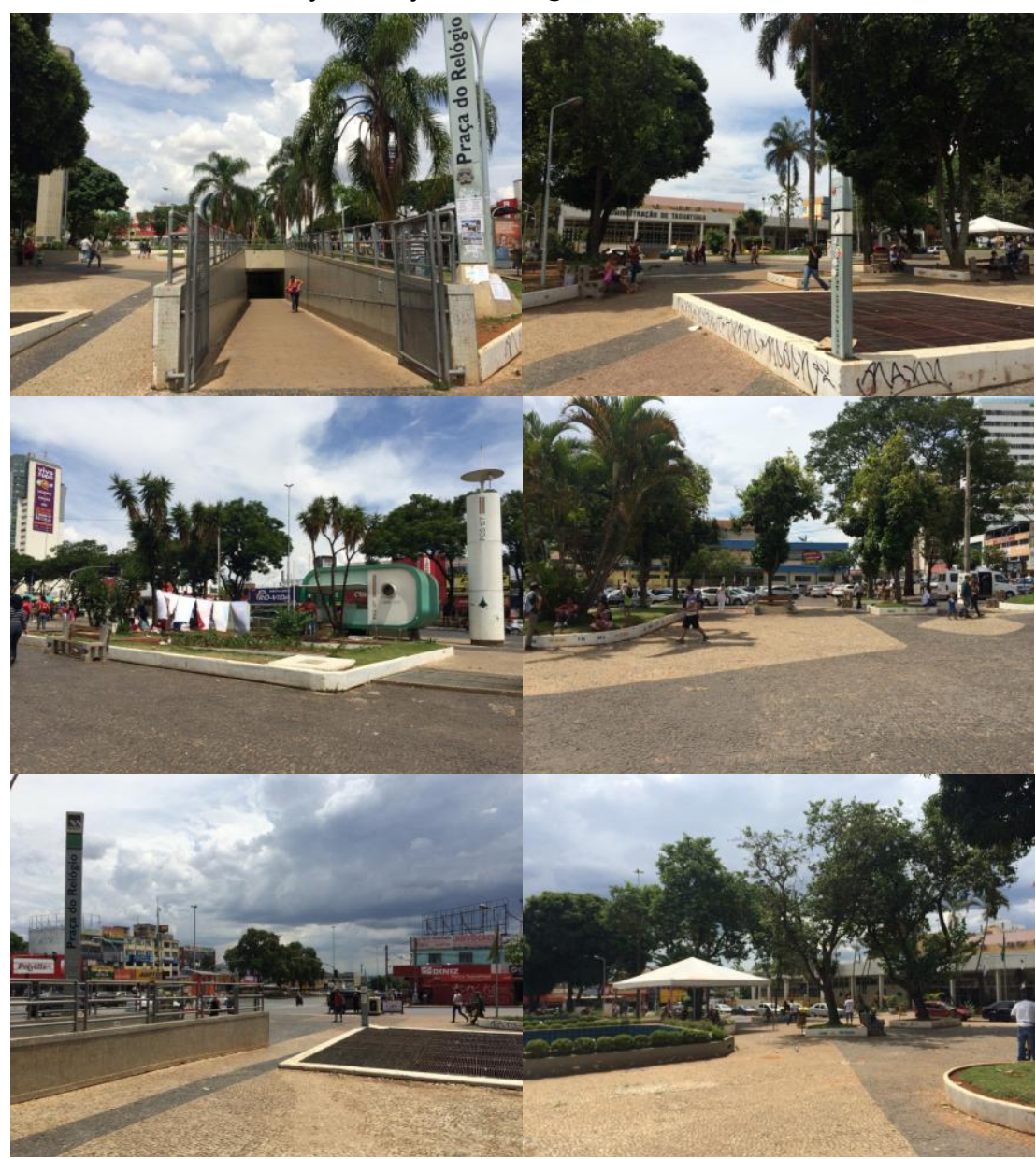

Fonte: Souza (2015).

Figura 5 - Isócronas na área de influência

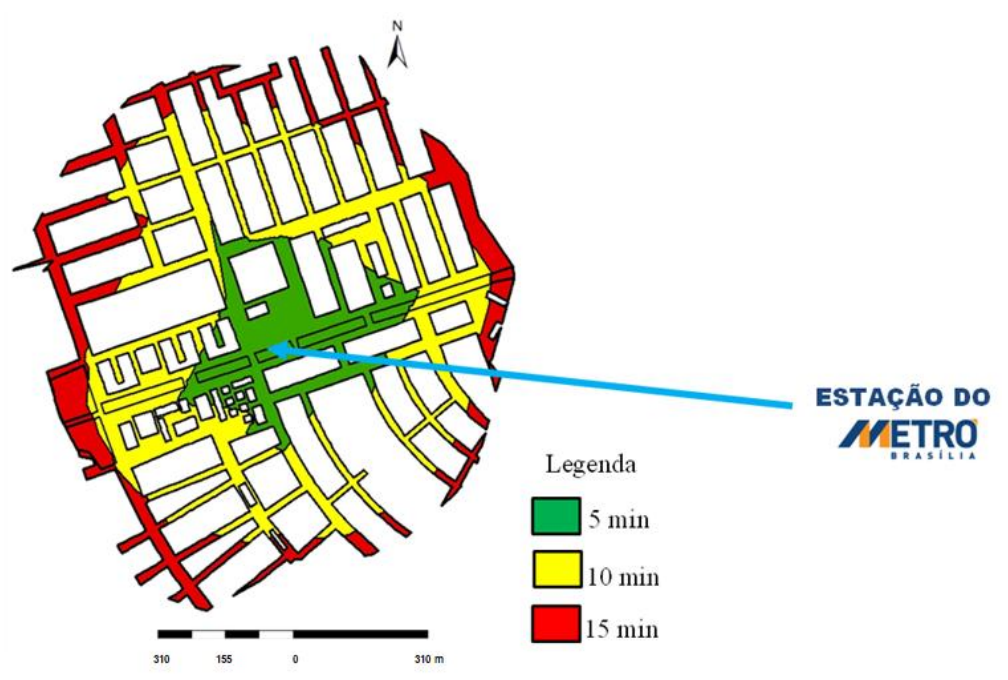

Fonte: Souza (2015).

No caso da Praça do Relógio, a análise da variável "área da isovista" indicou corredores como os campos de maior visibilidade, principalmente devido às interseções da malha viária, que foram decisivas para a formação desses campos visuais. As Figuras 6, 7 e 8 ilustram o tempo e as variáveis escolhidas, sempre 
levando em consideração o deslocamento realizado em minutos pelos pedestres. Os valores de maior visibilidade e integração visual são oriundos da distribuição cromática, em que as áreas vermelhas são as de melhor desempenho, enquanto as azuis apresentam restrições visuais.

Nota-se, a partir dos resultados, uma correlação entre os pontos visualmente mais integrados e a área da isovista. Sumariamente, os pontos mais integrados correspondem àqueles mais fáceis de serem vistos a partir da estação metroviária. Importante destacar as esquinas ou os cruzamentos nas proximidades da estação como locais de maior abrangência visual que devem prioritariamente receber UnIsP para orientar o pedestre.

A partir da análise da área da isovista, do raio máximo das isovistas e da integração visual, foi possível determinar a localização mais estratégica para a implantação das unidades de informação para pedestres. Essas UnIsP proporcionarão aos pedestres maior clareza e orientação do espaço urbano, além de propiciar uma continuidade do espaço ou trajeto a ser realizado, conforme demonstrado na Figura 9.

Figura 6 - Variáveis nos deslocamentos de 5 min

Praça do Relógio $5 \mathrm{~min}$

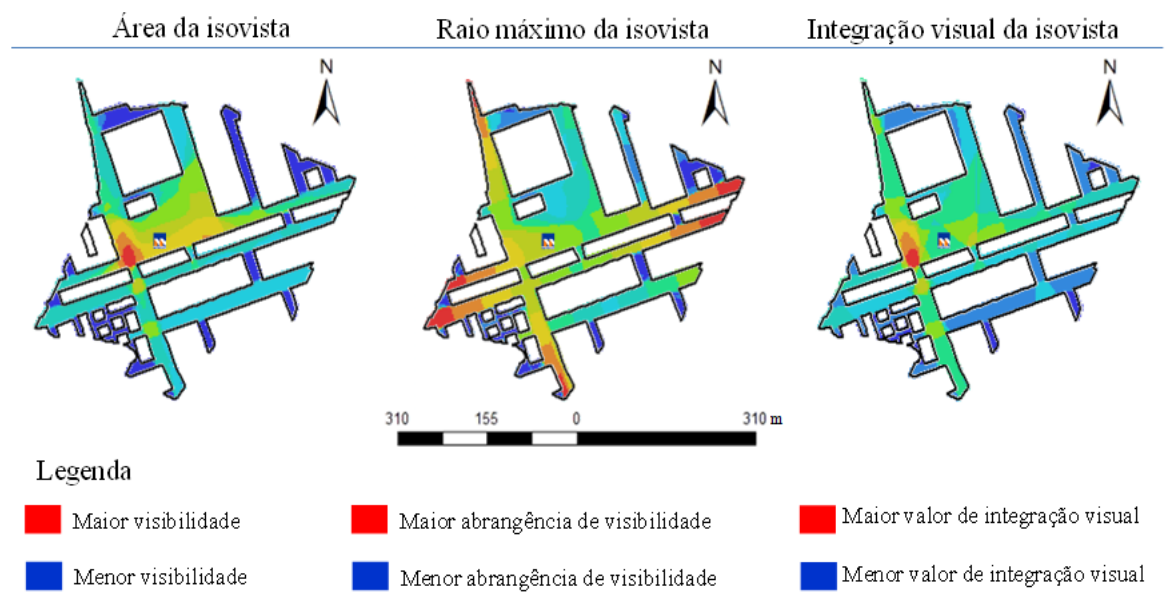

Fonte: Souza (2015).

Figura 7 - Variáveis nos deslocamentos de 10 min

Praça do Relógio $10 \mathrm{~min}$

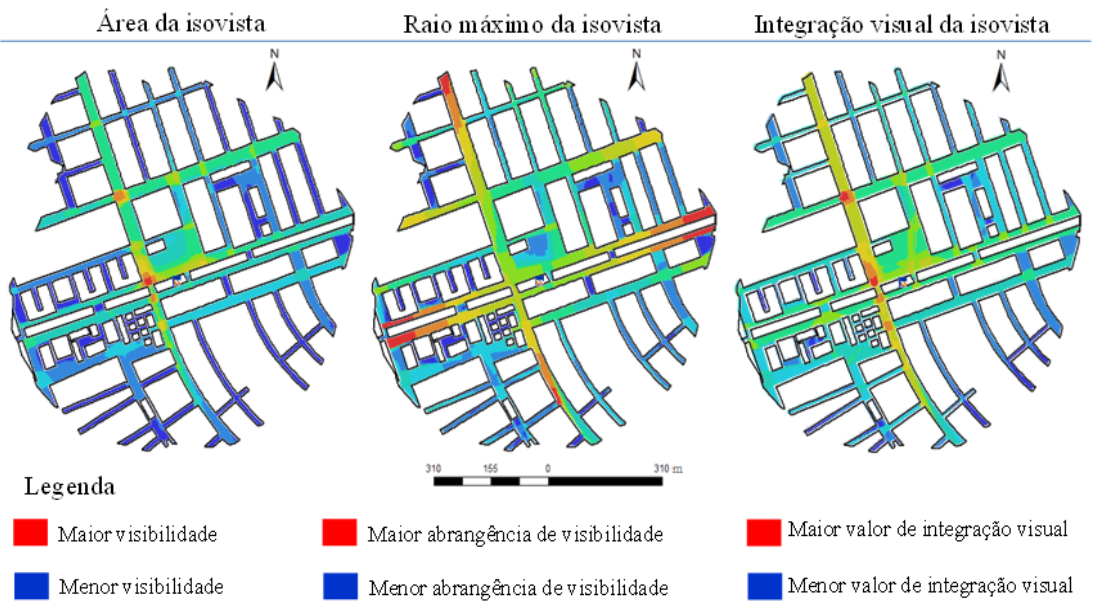

Fonte: Souza (2015). 
Figura 8 - Variáveis nos deslocamentos de 15 min

Praça do Relógio $15 \mathrm{~min}$

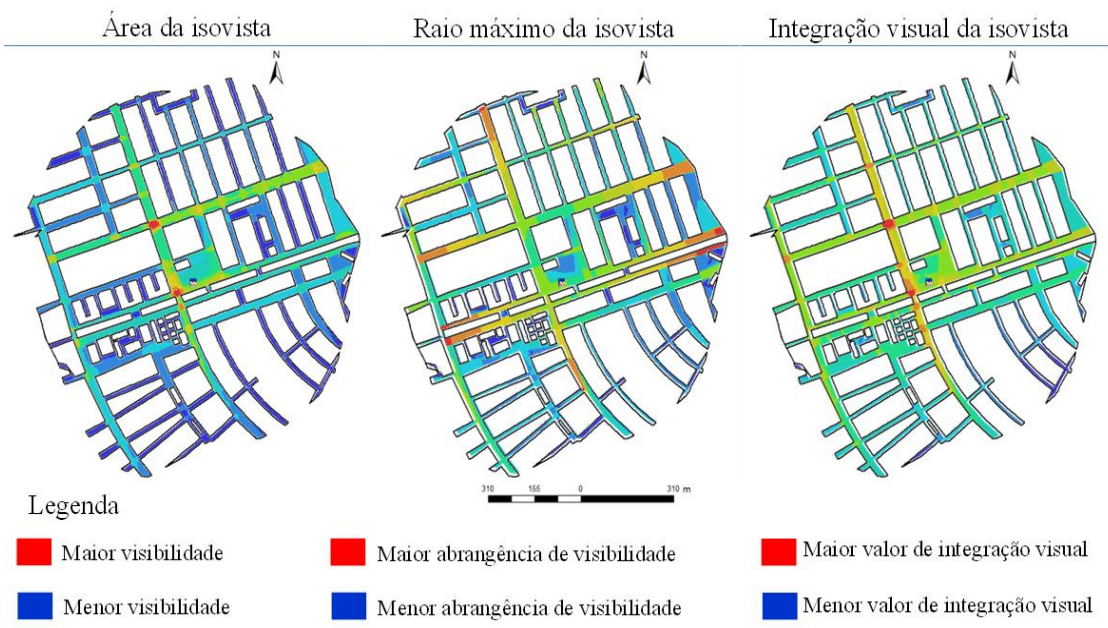

Fonte: Souza (2015).

Figura 9 - Localização das unidades de informação

Fonte: Souza (2015).

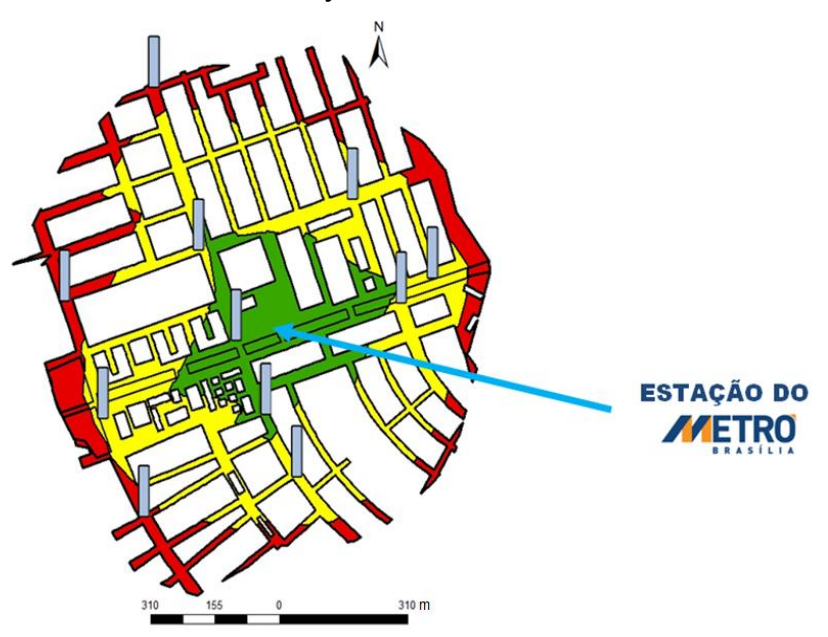

Observa-se que as áreas de maior visibilidade apresentadas na área de influência da Praça do Relógio coincidem com as áreas de maior circulação de pedestres identificadas visualmente, sem contagem volumétrica de pedestres. Na Figura 10 é apresentado esquematicamente qual seria o espaço físico real da implantação de cada UnIsP.

Depreende-se, a partir deste estudo de caso, que o método para a interpretação dos dados tem desempenho efetivo na análise das variáveis - área da isovista, raio máximo das isovistas e integração visual -, sendo pertinente priorizá-las na indicação de UnIsP, além de considerar a quantidade, a qualidade e o tipo (estático, móvel) de UnIsP. As conclusões, com base nas referências bibliográficas e no estudo de caso, preconizam que as isovistas podem ser usadas, até certo ponto, para simular como as pessoas se deslocam em ambientes reais, conforme também constatado por Mora, Astudillo e Bravo (2014), desde que o método não se limite ao aspecto físico dos espaços. Também podem ser incorporadas as análises de dados sobre a percepção do espaço pelos pedestres, visto que a natureza última da visão consiste não apenas em ver informações (de qualquer tipo), mas também em perceber a forma do que está sendo visto, quanto ao interesse das pessoas e seu nível de senso de orientação pelo espaço. Nesse sentido, o estudo abre possibilidades para o desdobramento de três vertentes de investigação. 
Figura 10 - Localização das UnlsP

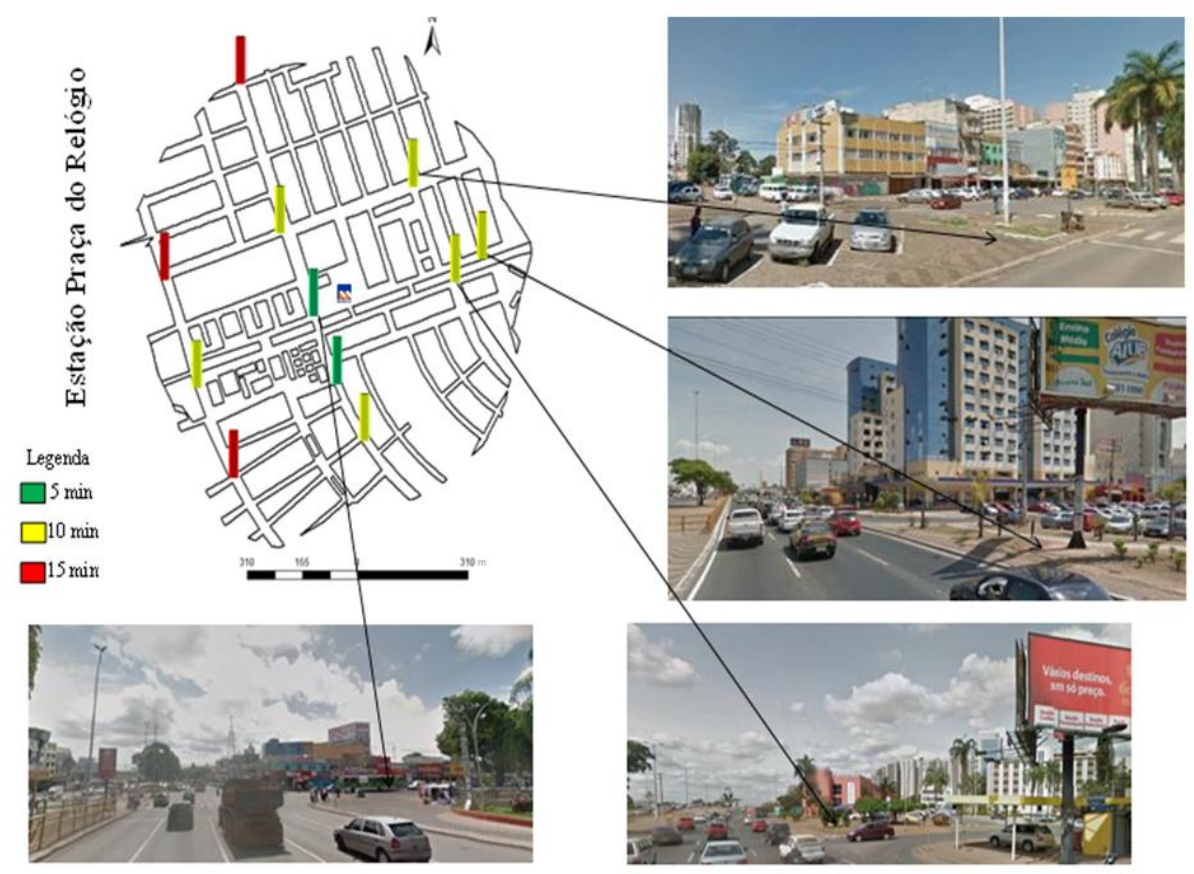

Fonte: Souza (2015).

Primeira, no método apresentado por Souza (2015), assim como em Batty (2001), após o trabalho inovador de Benedikt (1979), foi possível gerar os campos das isovistas, exibi-los de maneira padrão e desenvolver medidas baseadas no tempo de deslocamento, as quais detectam variações explicáveis e significativas sobre os espaços públicos e revelam um conjunto de medidas espaciais que refletem uma mistura sutil da geometria física do espaço com a dinâmica local do movimento visual. A variação em escala (5 min, 10 min e 15 min a partir das estações) e as UnIsP em níveis distintos podem interagir para uma melhor experiência dos pedestres nos seus deslocamentos. E, quanto a este último aspecto, o método proposto por Souza (2015) contribui ao propiciar interpretações da forma como o pedestre pode perceber visualmente a continuidade do espaço.

Ainda, os resultados apontados para o estudo de caso - Estação Praça do Relógio - confirmam, assim como em Ying et al. (2008), que os movimentos dos fluxos de pedestres também são afetados pela presença ou pela ausência de determinadas estruturas, cujos comportamentos não são, em grande escala, previstos pelos planejadores. A título de ilustração, a disponibilidade de informações mostra-se especialmente relevante para usuários não habituais de determinado espaço urbano, como turistas ou visitantes (PEIXOTO, 2018). Esse grupo de pessoas, que necessitam de informações detalhadas da cidade, se sente mais confiante e pode planejar descolamentos otimizados a partir do momento em que encontra informações disponíveis.

Segunda, esse método (SOUZA, 2015), avaliado quanto à inter-relação entre propriedades espaciais de espaços públicos e comportamento de pedestres, forneceu informações sobre a relevância das variáveis do descritor espacial. E, assim, contribuiu para a produção de conhecimento, de interesse mútuo, tanto na ciência cognitiva quanto na comunidade de Sintaxe Espacial, em conformidade com o recomendado no estudo de Franz e Wiener (2005). O método, ao possibilitar capturar a experiência dos pedestres no espaço público, corrobora como ferramenta interdisciplinar para aplicação por planejadores urbanos e dos transportes, em prol da caminhabilidade nas cidades (TURNER et al., 2001). E, para expandir os quadros teóricos emergentes para explicar os fatores ambientais construídos no bem-estar dos pedestres, recomendase incorporar uma etapa ao método com medição dos efeitos psicofisiológicos relacionados à percepção espacial, ao estresse e à inclusão de outros dados comportamentais, como a frequência cardíaca dos participantes, em conformidade ao recomendado em Knöll e Miranda (2017).

Terceira e última vertente de investigação, a aplicação do método avança na indicação da localização física de UnIsP em espaços públicos nas imediações das estações de metrô. No entanto, conforme apontado nos estudos de Giseop, Ayoung e Youngchul (2019), como o espaço urbano é medido, suas características espaciais podem ser simuladas em $3 \mathrm{D}$, ter os resultados testados e comparados. Dadas as características 
espaciais em 3D, o espaço urbano se tornaria um espaço de dados útil para deixar as cidades inteligentes, analisar aspectos existentes e prever a influência nos cenários de planejamento.

\section{Conclusões}

A proposta demonstra originalidade ao utilizar a ferramenta de isovista, derivada da Sintaxe Espacial, em estudo de caso de cidade brasileira. Considerando que este estudo dá continuidade a outros estudos de análise espacial, entende-se que a originalidade está na aplicação, que poderá ser replicada em outros pontos dos percursos nas imediações de terminais de diferentes modos de transportes, em que a presença dos elementos de comunicação espacial, UnIsP, é fundamental para garantir boas condições de caminhabilidade no ambiente construído.

Diante dos resultados apresentados e partindo-se do pressuposto de que as informações, quando bem localizadas, proporcionam melhor apropriação do espaço e deslocamento contínuo e orientado para os indivíduos, o presente estudo apresentou-se eficaz. A aplicação do método na Estação Praça do Relógio do metrô localizado em Taguatinga, em Brasília, aponta para resultados satisfatórios, admitindo potencial uso da ferramenta por gestores púbicos e planejadores no futuro e também revisão das estruturas atuais, possibilitando a localização estratégica de informações aos pedestres para orientação e otimização dos percursos.

O método UnIsP forneceu informações sobre a relevância das variáveis do descritor espacial; no entanto, recomenda-se:

(a) incorporar uma etapa ao método com medição dos efeitos relacionados à percepção dos pedestres quanto à localização das unidades;

(b) indicar os requisitos necessários quanto à informação, à forma de comunicação e ao tipo de materiais; e

(c) apontar os tipos de recursos visuais das UnIsP mais adequados ao perfil dos pedestres, podendo ser considerados aspectos, como, por exemplo, da diversidade - deficiência física e faixa etária.

Por fim, recomenda-se que a instalação de UnIsP seja realizada considerando prioritariamente o comportamento dos pedestres quanto à dimensão dos fluxos que circulam nas áreas de influência; aos tipos de informações requeridas; ao posicionamento das UnIsP; e à adaptabilidade dos pedestres na leitura dessas UnIsPcomo marcos visuais. Vale ressaltar que a aplicabilidade do método não se limita ao sistema metroviário de transporte, sendo possível sua aplicação, com as devidas adaptações, aos terminais e aos pontos de parada dos demais modos de transporte público.

\section{Referências}

AMIDON, E. L.; ELSNER, G. H. Delineating landscape view areas: a computer approach. Washington, DC: US Department of Agriculture, 1968. Forest Research Note PSW-180.

BARROS, A. P. B. G. Diz-me como andas que te direi onde estás: inserção do aspecto relacional na análise da mobilidade urbana para o pedestre. Brasília, 2014. 372 f. Tese (Doutorado em Transportes) Universidade de Brasília, 2014.

BARROS, A. P. B. G. Estudo exploratório da sintaxe espacial como ferramenta de alocação de tráfego. Brasília, 2006. 171 f. Dissertação (Mestrado em Transportes) - Universidade de Brasília, Brasília, 2006.

BARROS, A. P. B. G. et al. Metodologia para a análise da mobilidade na Universidade de Brasília. In: CONGRESSO NACIONAL DE PESQUISA E ENSINO EM TRANSPORTES, 23., Vitória, 2009. Anais [...] Vitória: Anpet, 2009.

BARROS, A. P. B. G.; MEDEIROS, V. A. S. Sustainable urban mobility: (A)synchrony between Subway Systems. In: WORLD CONFERENCE ON TRANSPORT RESEARCH, 2013. Proceedings [...] Rio de Janeiro: UFRJ, 2013.

BATTY, M. Exploring isovist fields: space and shape in architectural and urban morphology. Environment and planning B: Planning and Design, v. 28, n. 1, p. 123-150, 2001.

BENEDIKT, M. L. To take hold of space: isovists and isovist fields. Environment and Planning B: Planning and Design, v. 6, n. 1, p. 47-65, 1979. 
CARMO, C. L.; RAIA JUNIOR, A. A.; NOGUEIRA, A. D. A. Teoria da Sintaxe Espacial e suas aplicações na área de circulação e transportes. In: CONGRESSO LUSO-BRASILEIRO PARA O PLANEJAMENTO URBANO, REGIONAL, INTEGRADO E SUSTENTÁVEL, 5., Brasília, 2012. Anais [...] Brasília: Universidade de Brasília, Faculdade de Arquitetura e Urbanismo, 2012.

CONFEDERAÇÃO NACIONAL DA INDÚSTRIA. Pesquisa: retratos da sociedade brasileira, locomoção urbana. Brasília: CNI, 2011.

COMPANHIA DE PLANEJAMENTO DO DISTRITO FEDERAL. Anuário Estatístico do Distrito

Federal. Brasília, 2016. Disponível em: http://www.codeplan.df.gov.br/areas-tematicas/anuarioestatisticodo-df.html. Acesso em: 10 out. 2017.

ECK, R. W. Pedestrian. In: KUTZ, M. Handbook of transportation engineering. New York: McGrawHill Handbooks, 2004.

ELOY, S. Ferramentas de apoio à análise da geometria do espaço arquitetônico: sintaxe espacial e gramáticas de forma. Revista Aproged, v. 29, p. 3-14, 2011.

ERA, R. T. Improving pedestrian accessibility to public space through space syntax analysis. In:INTERNATIONAL SPACE SYNTAX SYMPOSIUM, 8., Santiago, 2012. Proceedings [...] Santiago, PUC, 2012.

FAYUMI, B. Pedestrian movement and safety. Urban Transportation Planning and Management CIVE5307. Carleton University. Department of Civil \& Environmental Engineering, 2011.

FEDERAL HIGHWAY ADMINISTRATION. Manual on Uniform Traffic Control Devices, 2009. Disponível em: http://mutcd.fhwa.dot.gov/. Acesso em: 3 ago. 2014.

FRANZ, G.; WIENER, J. M. Exploring isovist-based correlates of spatial behavior and experience. In: INTERNATIONAL SPACE SYNTAX SYMPOSIUM, 5., Delft, 2005. Proceedings [...] Delft: TU Delft Press, 2005.

FUJITANI, M.; KISHIMOTO, T. A study about the pedestrian distribution in the commercial buildings by the location of stores and the structure of the walking space. In: INTERNATIONAL SPACE SYNTAX SYMPOSIUM, 8., Santiago, 2012. Proceedings [...] Santiago de Chile: PUC, 2012.

GEHL, J. Cidades Para Pessoas. São Paulo: Perspectiva, 2013.

GISEOP, K. I. M.; AYOUNG, K. I. M.; YOUNGCHUL, K. I. M. A new 3D space syntax metric based on 3D isovist capture in urban space using remote sensing technology. Computers, Environment and Urban Systems, v. 74, p. 74-87, 2019.

HILLIER, B.; HANSON, J. The social logic of space. Londres: Cambridge University Press, 1984.

INSTITUTO BRASILEIRO DE GEOGRAFIA E ESTATÍSTICA. Censo demográfico. Rio de Janeiro, 2015.

KNÖLL, M.; MIRANDA, M. H. The Luisenplatz study: the relationship between visual fields and perceived stress in a public transport hub. In: INTERNATIONAL SPACE SYNTAX SYMPOSIUM, 11., Lisboa, 2017. Proceedings [...] Lisboa, 2017.

LYNCH, K. Managing the Sense of Region. Cambridge: MIT Press, 1976.

MEDEIROS, V. Urbis Brasiliae: o labirinto das cidades brasileiras. Brasília: Ed. UnB, 2013.

METRÔ-DF. O Metrô-DF e seu público. Brasília, 2019. Disponível em: http://www.metro.df.gov.br/?page_id=40075. Acesso em: 5 dez. 2019.

MORA, R.; ASTUDILLO, H.; BRAVO, S. Looking ahead: a vision-based software for predicting pedestrian movement. Ingeniería e Investigación, v. 34, n. 1, p. 79-82, 2014.

NOGUEIRA, A. D. Morfologia urbana através da sintaxe espacial e do fluxo de pedestres em território universitário: o câmpus da UFSCar. São Carlos, 1998. 200 f. Dissertação (Mestrado em Engenharia Urbana) - Centro de Ciências Exatas e Tecnologia, Universidade Federal de São Carlos, São Carlos, 1998.

O'SULLIVAN, D.; MORRISON, A.; SHEARER, J. Using desktop GIS for the investigation of accessibility by public transport: an isochrome approach. International Journal of Geographical Information Science, v. 14, n. 1, p. 85-104, 2000. 
PEIXOTO, N. E. S. Identificação dos parâmetros da infraestrutura de transporte urbano que influenciam na mobilidade do turista. Brasília, 2018. Dissertação (Mestrado em Transportes) - Programa de Pós-Graduação em Transportes, Universidade de Brasília, Brasília, 2018.

PEREIRA, R. H. et al. O uso da Sintaxe Espacial no desempenho do transporte urbano:limites e potencialidades. Brasília: IPEA, 2011. Texto para Discussão 1630.

RAFORD, N.; RAGLAND, D. R. Space Syntax: an innovative pedestrian volume modeling tool for pedestrian safety. University of California, 2003. Disponível em: http//repositories.cdlib.org/its/tsc/UCBTSC-RR-2003-11. Acesso em: 6 ago. 2014.

SOUZA, A. C. S. Localização espacial de unidades de informação para o deslocamento de pedestres utilizando isovistas. Brasília, 2015. Dissertação (Mestrado em Transportes) - Departamento de Engenharia Civil e Ambiental, Universidade de Brasília, Brasília, 2015.

TURNER, A. et al. From isovists to visibility graphs: a methodology for the analysis of architectural space. Environment and Planning B: Planning and Design, v. 28, n. 1, p. 103-121, 2001.

VUKAN, R. Urban transit systems and technology. New Jersey: John Wiley \& Sons, 2007.

YING, S. et al. Analysis of relationship between pedestrian facilities and urban morphology based on visibility. In: GEOINFORMATICS AND JOINT CONFERENCE ON GIS AND BUILT ENVIRONMENT: THE BUILT ENVIRONMENT AND ITS DYNAMICS, Guangzhou, 2008. Proceedings [...] Guangzhou, 2008.

\title{
Agradecimentos
}

Os autores agradecem ao Grupo de Pesquisa Comportamento em Transportes e Novas Tecnologias (CTNT) do Programa de Pós-Graduação em Transportes da Universidade de Brasília. A primeira autora agradece ao Conselho Nacional de Desenvolvimento Científico e Tecnológico (CNPq) pela bolsa concedida durante a realização da pesquisa.

Adriana Cristina da Silva Souza

Programa de Pós-Graduação em Transportes | Universidade de Brasília | Campus Universitário Darcy Ribeiro, Prédio SG-12, $1^{\circ}$ Andar | Brasília - DF - Brasil | CEP 70910-900 | Tel.: (61) 3107-0975 | E-mail: souza.ppgt@gmail.com

Pastor Willy Gonzales Taco

Programa de Pós-Graduação em Transportes | Universidade de Brasília | E-mail: pwgtaco@gmail.com

Ana Catarina Ferreira Lima

Faculdade de Arquitetura e Urbanismo | Universidade de Brasília | Campus Universitário Darcy Ribeiro ICC Norte, Gleba A | Brasília - DFBrasil | CEP 70904-970 | Tel.: (61) 3107-7431 | E-mail: anacatarina.lima16@gmail.com

Elisangela Aparecida Machado da Silva

Programa de Pós-Graduação em Transportes | Universidade de Brasília | E-mail: elisangela-machado@hotmail.com

\author{
Ambiente Construído \\ Revista da Associação Nacional de Tecnologia do Ambiente Construído \\ Av. Osvaldo Aranha, $99-3^{\circ}$ andar, Centro \\ Porto Alegre - RS - Brasil \\ CEP $90035-190$ \\ Telefone: +55 (51) 3308-4084 \\ Fax: +55 (51) 3308-4054 \\ www.seer.ufrgs.br/ambienteconstruido \\ E-mail: ambienteconstruido@ufrgs.br
}

